\title{
$\operatorname{RDS}\left({ }^{\circ}\right)$
}

Vol. 27, n. 2, jul/dez, 2021

Revista Desenvolvimento Social

ISSN: 2179-6807 (online)

\section{MANTER A ESPERANÇA: \\ UM PEQUENO ALMANAQUE DE MENSAGENS DE CORAGEM E ESPERANÇA, PARA TEMPOS DE PANDEMIA}

Carlos Rodrigues Brandão ${ }^{1}$

Recebido em: $13 / 10 / 2021$

Aprovado em: 20/12/2021

Saibamos trocar o verbo passivo "esperar", pelo verbo ativo "esperançar".

Em todas as partes e a todo o momento ouvimos e vemos pessoas dizendo de diferentes maneiras que "estamos vivendo um tempo escuro"; "estamos atravessando um tempo de tão poucas esperanças!"

E é sobre isso quero lembrar algo. Apenas, desta vez, o que trago como uma mensagem não são palavras minhas.

Preferi escolher alguns escritos de outras pessoas. E em todas elas, com acentos e palavras semelhantes ou diferentes, trago algo de resistência, de resiliência, de coragem e de esperança.

Que a primeira lembrança seja de um antropólogo, e também um educador: Darcy Ribeiro.

Antes de nos deixar ele escreveu isto:

\footnotetext{
${ }^{1}$ Licenciado em psicologia e Psicólogo pela Pontifícia Universidade Católica do Rio de Janeiro (1965); mestre em antropologia pela Universidade de Brasília (1974). doutor em ciências sociais pela Universidade de São Paulo (1980); livre docente em antropologia do simbolismo pela Universidade Estadual de Campinas. Realizou pós-doutorado na Universidade de Perugia e na Universidade de Santiago de Compostela. É "fellow" do St. Edmund's College da Universidade de Cambridge. Atualmente é professor colaborador do Programa de Pós-Graduação em Antropologia da Universidade Estadual de Campinas (UNICAMP), professor colaborador do POSGEO da Universidade Federal de Uberlândia (UFU) e professor visitante da Universidade Estadual de Goiás. Possui experiência na área de antropologia, com ênfase em antropologia camponesa, antropologia da religião, cultura popular, etnia e educação, com foco na educação popular. É Comendador do Mérito Científico pelo Ministério de Ciência e Tecnologia, doutor honoris causa pela Universidade Federal de Goiás, doutor honoris causa pela Universidad Nacional de Lujan (Argentina), professor emérito da Universidade Federal de Uberlândia, e professor emérito da Universidade Estadual de Campinas. Escreveu artigos e livros nas áreas de antropologia, educação e literatura. E-mail: carlosdecaldas@gmail.com.
} 
Sou um homem de Causas. Vivi sempre pregando, lutando, como um cruzado, por causas que me comovem. São muitas, demasiadas: a salvação dos índios, a escolarização das crianças, a reforma agrária, o socialismo em liberdade, a universidade necessária... Na verdade, somei mais fracassos que vitórias nas minhas lutas. Mas isso não importa. Seria horrível ter estado ao lado dos que se venderam nessas batalhas.

Outra mensagem é mais recente. Ela é de um sociólogo, um militante europeu de causas sociais, e um homem de grande presença aqui na América Latina. Um alguém que, "vindo do Norte", pensa o mundo a partir das "Cartografias do Sul", ou seja, as nossas.

Na Nona carta às Esquerdas, de seu livro: Trece cartas a las izquierdas, Boaventura de Souza Santos escreveu isto no último parágrafo, na página 80 do livro: “Esperar sem esperança é a maior maldição que pode cair sobre um povo. E a esperança não se inventa: ela se constrói com inconformismo, rebeldia competente e alternativas reais frente á situação presente".

Eis agora um breve e sábio pensamento do líder sul-africano, Nelson Mandela: "Tudo é impossível. Até começar a acontecer".

Quero lembrar também Jean-Paul Sartre, um pensador de quem li poucas coisas, mas aprendi do que li. Sartre morreu em abril de 1980 e, quarenta anos depois eu quero recordá-lo agora, em 2020. Em uma última entrevista, publicada em Português pelo jornal O Estado de São Paulo, ele disse isto que eu transcrevo aqui. Uma breve e sábia lembrança de Emily Dickson, a poeta norte-americana: “A esperança tem asas. Faz a alma voar... E nunca desiste. Nunca."

Jean-Paul Sartre, filósofo e militante, escreveu isto pouco antes de partir:

O mundo parece feio, mau e sem esperança. Esse seria o desespero de um velho que já morreu dentro de nós. Mas eu resisto, e sei que morrerei de esperança, dentro da esperança. Mas essa esperança, teremos que fundá-la. É preciso tentar explicar por que é que o mundo de agora, que é horrível, não passa de um momento no longo desenvolvimento histórico; e que a esperança foi sempre uma das forças dominantes das revoluções e das insurreições, e como sinto ainda, a esperança, como a minha concepção do futuro. (Está em: O Estado de São Paulo, 18 de abril de 1980, página 21). 
Jean-Paul Sartre escreveu também esta passagem que transcrevo aqui:

O essencial não é o que foi feito do homem, mas o que ele faz daquilo que fizeram dele. $O$ que foi feito dele são as estruturas, os conjuntos significantes estudados pelas ciências humanas. O que ele faz é a sua própria história, a superação real destas estruturas numa práxis totalizadora.

Algo que Eduardo Galeano traduziu com estas palavras:

Nossa autêntica identidade coletiva nasce do passado e se nutre dele pegadas sobre as quais caminham nossos pés, passos que representem nossas andanças de agora - mas não cristaliza na nostalgia. Somos o que fazemos, e, sobretudo o que fazemos para mudar o que somos: nossa identidade reside na ação e na luta. Por isso a revelação do que somos implica na denúncia do que nos impede de ser o que podemos ser.

Uma breve passagem de Rubem Alves:

(Uma) questão, às vezes, me é dirigida da seguinte forma: "Você tem esperança?" - especialmente quando se trata de educação ou de ecologia, digo o seguinte: "há muito tempo que não me faço esta pergunta: se tenho esperança ou não de que as coisas deem certo". Encontro a minha alegria em realizar a semeadura. $\mathrm{O}$ ato de semear, em si mesmo, é um ato de alegria. Isso me basta.

E, ainda fiquemos com um poema de Otávio Paz:

A alegria amadurece como um fruto

$O$ fruto amadurece até ser sol

$\mathrm{O}$ sol amadurece até ser homem

O homem amadurece até ser astro

Nunca a luz repartiu-se em tantas luzes,

As árvores, as ruas, as montanhas

Água terra e sol são um só corpo

A hora e o seu sino se dissolvem

As pedras as paisagens se evaporam

Todos se foram sem voltar o rosto

E ardemos, e não deixamos rastro. 
De Clarisse Lispector, de quem celebramos os seus "100 anos de vida", eu trago uma mensagem extrema de esperança. Algo que deve estar vivo e presente em quem abriu as velas de seu barco... e partiu: "Ao soar dos seres e das coisas, que deus abrisse seu coração, que lhe permitisse olhar para dentro de si, e o medo expulso, pudesse enfim dizer à morte, vivi!".

E também este momento em que ela escreve esperançosamente sobre o momento em que encontra no outro o seu porto de chegada.

Não é à toa que entendo os que buscam caminho. Como busco arduamente o meu! E como hoje busco com sofreguidão e aspereza o meu melhor modo de ser, o meu atalho, já que não ouso mais falar em caminho. Eu que tinha querido o Caminho, com letra maiúscula, hoje me agarro ferozmente à procura de um modo de andar, de um passo certo. Mas o atalho com sombras refrescantes e reflexo de luz entre as árvores, o atalho onde eu seja finalmente eu, isso eu não encontrei. Mas sei de uma coisa: meu caminho não sou eu, é outro, é os outros. Quando eu puder sentir plenamente o outro estarei salva e pensarei: eis o meu porto de chegada.

E eis aqui algo de esperança em um "auto popular", umnmomento do Coronel de Macambira, de Joaquim Cardoso.
As asas que ali caíram
Foram asas que me deram.
Minhas asas verdadeiras,
As que comigo vieram,
No chão rasteiro e sem fim
Jamais poderão cair.
São as asas da esperança
De um futuro que há de vir.

Uma mensagem de extrema beleza e mais do que oportuna de Ailton Krenak. Ele não fala da esperança. Mas fala da vida. E quem fala como ele da vida, fala da coragem da esperança.

A vida não é para ser útil. Isso é uma besteira. A vida é tão maravilhosa que a nossa mente tenta dar uma utilidade para ela. A vida é fruição. A vida é uma dança. Só que ela é uma dança cósmica e a gente quer reduzi-la a uma 
coreografia ridícula e utilitária, a uma biografia: alguém nasceu, fez isso, fez aquilo, fundou uma cidade, inventou o fordismo, fez a revolução, fez um foguete, foi para o espaço... tudo isso, gente, é uma historinha tão ridícula! A vida é mais do que tudo isso. (...) Nós temos de ter coragem de ser radicalmente vivos. E não negociar sobrevivência.

A esperança em uma versão ousadamente cristã. Ela nos vem de Molthamann, um teólogo protestante autor de uma Teologia da Esperança. E a passagem foi encontrada em um livro de Rubem Alves.

A esperança não considera as coisas como passadas, e sim enquanto progresso: coisas em movimento, com possibilidades de mudança. A ressurreição como realidade última, como um primum movens que arrasta a história, informa à consciência que o mundo está realmente aberto, progredindo. Em consequência, a esperança e a antecipação do futuro são modos realistas de se perceber o alcance de nossas verdadeiras possibilidades, e assim elas colocam tudo e movimento e em estado de mudança.

Raul Brandão, um escrito português, não fala da esperança. Mas fala da vida e do ardor por ela de uma tal maneira que a esperança está presente nisto que ele escreveu. É do livro: Se tivesse que recomeçar a Vida.

Se vale a pena viver a vida esplêndida - esta fantasmagoria de cores, de grotesco, esta mescla de estrelas e de sonho? ... Só a luz! Só a luz vale a vida! A luz interior ou a luz exterior. Doente ou com saúde, triste ou alegre, procuro a luz com avidez. A luz, para mim é a felicidade. Vivo de luz. Impregno-me, olho-a num êxtase. Valho o que ela vale. Sinto-me caído quando o dia amanhece baço e turvo. Sonho com ela e de manhã é a luz o meu primeiro pensamento. Qualquer fio me prende, qualquer reflexo me encanta.

E eis aqui algo derivado do inédito viável de Paulo Freire: escreveu:

A esperança da libertação não significa já a libertação. É preciso lutar por ela entre condições historicamente favoráveis. Se estas não existem, temos que lutar de forma esperançada para criá-las. A liberdade é uma possibilidade. Não é a sorte, nem o destino, nem a fatalidade. Neste contexto percebemos a importância da educação, para a decisão, para a ruptura, para a escolha, 
para a ética, a política, finalmente. Enquanto eu luto eu sou movido pela esperança!

Do romance Zorba, o Grego, trago esta passagem que não fala sobre a esperança, mas que é bastante esperançosa a respeito de como algumas pessoas podem ser.

Creio, Zorba, mas posso estar enganado, que há três espécies de homens: os que têm como objetivo de vida - como dizem eles - comer, beber, amar, enriquecer, ficar célebres. Depois há aqueles que tem por objetivo não só a sua própria existência, mas a de todos os homens. Sentem que todos os homens são iguais, como se fossem um só, e esforçam-se para esclarecê-los, para amá-los o mais que podem e para Ihes fazer o bem. Enfim, há aqueles cujo objetivo é viver a vida do universo inteiro: todos nós, homens, animais, plantas, astros, somos um só, somos apenas uma mesma substância que trava a mesma luta terrível. Que luta? Transformar a matéria em espírito.

A esperança se realiza na luta para tornar uma realidade social e esperança que nos move. Assim, eis o que, sem dizer a palavra "esperança", diz o poeta Bertolt Brecht: "Quem luta, pode perder. Quem não luta, já perdeu".

Eis aí. Algumas pessoas se foram em 2020, com a pandemia, ou por meio de outras formas de partir. Ficamos nós.

Ficamos nós! Fiquemos no fervor da vida; na presença solidária; no trabalho de cada dia; na ação de cada hora; na luta inevitável; na esperança inabalável.

Carlos Rodrigues Brandão (quase no final de 2020). 